\title{
Waist Circumference, Waist-Hip Ratio and Body Mass Index in Assessing Nutritional Status and Central Obesity of Adolescent
}

\author{
KanKana De* \\ Vidyasagar University, India \\ Submission: February 01, 2017; Published: March 15, 2017 \\ *Corresponding author: KanKana De, Vidyasagar University, India, Tel: 9474714273; Email: dekankana@gmail.com
}

\begin{abstract}
WHR is used as a measurement of obesity, which in turn is a possible indicator of other more serious health conditions. The WHO states that abdominal obesity is defined as a waist-hip ratio above 0.90 for males and above 0.85 for females, or a body mass index (BMI) above 30.0 .

Area of study and Sample size: Subjects are adolescent girls aged 10-19 years. They belong to Salboni Block which is one of blocks of Paschim Medinipur, Westbengal, Participants of socioeconomic data are collected through structured questionnaire, anthropometric data are collected through different instruments, cross section study is done over 1009 girls.

Result: Table 1 represents body mass index and waist hip ratio distribution, Table $2 \& 3$ found significant relation with percent body fat and BMI, waist-hip ratio, waist height ratio.

Conclusion: Central obesity had significant effect on chronic heart diseases. Those girls have shown centrally obese in his study; they have chances to experience heart disease in future.
\end{abstract}

Keywords: Body mass index; Waist-hip ratio; Undernutrition

\section{Introduction}

Assessment of nutritional status of adolescent is done by anthropometric measurements. Body weight, BMI, mid-arm muscle circumference, and skin fold thickness all are different anthropometric measurement. Cardio metabolic risk factor has associated with waist circumference. This will be the general adiposity as will be is measured by body mass index (BMI) [1]. A waist circumference of $>94 \mathrm{~cm}$ in men and $>80 \mathrm{~cm}$ in women, an increased risk of diseases such as coronary heart disease(CHD). This measurement is widely used in the classification of obesity. Body composition is changing in every stage of life and is reflected in measurement. The WHR has been used as an indicator or measure of health, and the risk of developing serious health conditions. WHR correlates with fertility (with different optimal values for males and females). WHR is used as a measurement of obesity, which in turn is a possible indicator of other more serious health conditions. The WHO states that abdominal obesity is defined as a waisthip ratio above 0.90 for males and above 0.85 for females, or a body mass index (BMI) above 30.0 [2]. The National

Institute of Diabetes, Digestive and Kidney Diseases (NIDDK) states that women with waist-hip ratios of more than 0.8 , and men with more than 1.0 [3], are at increased health risk because of their fat distribution. According to the Centres for Disease Control and Prevention-United States (CDC-US) growth charts, which are relatively specific, the 85 th percentile is the cut off point for being overweight, whereas the 95th percentile is the cut off point for obesity $[14,15]$.. The sensitivity and specificity of each WHR level for the detection of hypertension, dyslipidemia, diabetes, and two or more of these risk factors were calculated by creating dichotomous variables for each WHR value [3].

BMI and WC are two important predictors for teenagers to become overweight and obese [4]. Receiver-operating characteristic (ROC) analysis is a very useful tool for visualizing is evaluating classifiers and utilized to evaluate the accuracy of a diagnostic test by summarizing the potential of the test to discriminate between the absence and presence of a 
health condition. Waist-to-height ratio (WHTR) was the best discriminator for hypertension, diabetes, and dyslipidemia in both sexes [5]. Waist circumference a tool to assessing will be assess abdominal fat and health status. In postmenopausal women estrogens deficiency plays an important role in the change of body composition and fat tissue distribution [6].

Waist circumference, waist-hip ratio and waist- height ratio, have been suggested as being superior to BMI in predicting CVD risk [7].

\section{Materials and Methods}

\section{Area of study and sample size}

Subjects are adolescent girls aged 10-19 years. They belong to Salboni Block which is one of the blocks of Paschim Medinipur, Westbengal, Participants of socioeconomic data are collected through structured questionnaire; anthropometric data are collected through different instruments; cross section study is done over 1009 girls.

Height was measured to the nearest $0.1 \mathrm{~cm}$ by using a stadiometer (Holtain Ltd., Crymych, UK) when the subjects stood wearing socks and with their heads in the Frankfort horizontal plane. Weight was measured to the nearest $0.1 \mathrm{~kg}$ with an electronic portable scale (Secadelta, Model 707). BMI was calculated as weight $(\mathrm{kg})$ divided by height $(\mathrm{m})$ squared. A metal tape was used to measure the circumference of the buttocks. Waist circumference was measured at a level midway between the lowest rib and the crista iliaca superior. The measurement was carried out at the end of a normal expiration while the subject stood upright with feet together and arms hanging freely at the sides. Hip circumference was measured at the maximum point below the waist, without compressing the skin. WHR was calculated by dividing the waist measurement by the hip measurement $[8,9]$.

Derivation of the ROC curves was based on a method by Obuchowski [10] for continuous-scale of gold standards. ROC analyses were performed in order to evaluate the general performance of the BMI, WC and WHR. The percentage of body fat was considered as the reference standard for the ROC curve analysis of BMI for girls WC rib measures displayed the strongest associations with non-optimal lipid and lipoprotein levels, high blood pressure, insulin resistance, impaired fasting glucose, a clustering of metabolic risk features and type 2 diabetes, in both genders. Rib-derived indices improved discrimination of type 2 diabetes.

WC and WHR were performed by employing a nonparametric approach, which was implemented in Statistical Packages for Social Sciences (SPSS) Two-sided p values were considered statistically significant at $\mathrm{p}<.005$.

\section{Results}

Mean waist circumference is 78.32(6.32) and mean Hip circumference is 84.64 (6.57 In late adolescent phase girls are found centrally obese. 827 girls in overall study is centrally obese, study represents that at age 14,15. 16 girls are centrally obese, 90 girls centrally obese at age 15 years. 80 girls are under nutrient will be nutrition among 1009 girls, Table 1 represents body mass index and waist hip ratio distribution, Table $2 \& 3$ is found significant relation with percent body fat and BMI, waisthip ratio, waist height ratio.

Table 1: Distribution of body-mass index (BMI) and waist to hip ratio (WHR) participating subjects.

\begin{tabular}{|c|c|c|c|}
\hline \multirow{2}{*}{ BMI status } & \multicolumn{2}{|c|}{ WHR } & \multirow{2}{*}{ Total } \\
\cline { 2 - 3 } & $\mathbf{1}$ & $\mathbf{2}$ & \\
\hline 1 & 3 & 25 & 28 \\
\hline 2 & 5 & 29 & 34 \\
\hline 3 & 13 & 140 & 153 \\
\hline 4 & 77 & 620 & 697 \\
\hline 5 & 0 & 3 & 3 \\
\hline Total & 98 & 817 & 915 \\
\hline
\end{tabular}

1=CEDI, 2=CEDII 3=CEDIII 4=normal 5=obese; Waist-hip ratio$1=$ normal, $2=$ undernutrition.

Table 2: Areas and $95 \% \mathrm{Cl}$ of Receiver operating Curve.

\begin{tabular}{|c|c|c|c|c|c|}
\hline \multirow{2}{*}{ Test Result Variable(s) } & Area & Std. Error & \multirow{2}{*}{ Asymptotic Sig. } & \multicolumn{2}{|c|}{ Asymptotic 95\% Confidence Interval } \\
\cline { 3 - 5 } & Waist circumference & 0.231 & 0.017 & 0 & Lower Bound \\
\hline Waisthip ratio & 0.463 & 0.034 & 0.23 & 0.197 & 0.264 \\
\hline BMI & 0.287 & 0.03 & 0 & 0.397 & 0.53 \\
\hline
\end{tabular}

The test result variable(s): Waist circumference, waist hip ratio, BMI has at least one tie between the positive actual state group and the negative actual state group. Statistics may be biased.
a. Under the nonparametric assumption
b. Null hypothesis: true area $=0.5$ 
Table 3: Correlations between anthropometric index with percent body fat.

\begin{tabular}{|c|c|c|c|c|}
\hline & & Waist Circumference & BMI & Waisthip Ratio \\
\hline \multirow{3}{*}{ Waist Circumference } & Pearson Correlation & 1 & $0.232^{* *}$ & $0.170^{* *}$ \\
\hline & Sig. (2-tailed) & & 0 & 0 \\
\hline & $\mathrm{N}$ & 1008 & 1008 & 1004 \\
\hline \multirow{3}{*}{ BMI } & Pearson Correlation & $0.232^{* *}$ & 1 & 0.016 \\
\hline & Sig. (2-tailed) & 0 & & 0.622 \\
\hline & $\mathrm{N}$ & 1008 & 1018 & 1010 \\
\hline \multirow{3}{*}{ Waisthip ratio } & Pearson Correlation & $0.170^{* *}$ & 0.016 & 1 \\
\hline & Sig. (2-tailed) & 0 & 0.622 & \\
\hline & $\mathrm{N}$ & 1004 & 1010 & 1010 \\
\hline
\end{tabular}

${ }^{* *}$ Correlation is significant at the 0.01 level (2-tailed).

\section{Discussion}

Yang et al. and Neovious et al. also have used ROC curves to evaluate obesity from BMI, WC and WHR data. They also found that BMI and WC indices were suitable for diagnostic tests; however, WHR was less useful. This trend is observed in our study in line with that observed during previous investigations by the above mentioned authors. Yang et al. and Neovious et al after also write have used ROC curves to evaluate obesity from BMI, WC and WHR data. They also found that BMI and WC indices were suitable for diagnostic tests; however, WHR was less useful. This trend observed in our study is in line with that observed during previous investigations by the above mentioned authors. Figure 1 of Roc curve shown accuracy chronic energy deficiency and waist -hip ratio have positive relation.

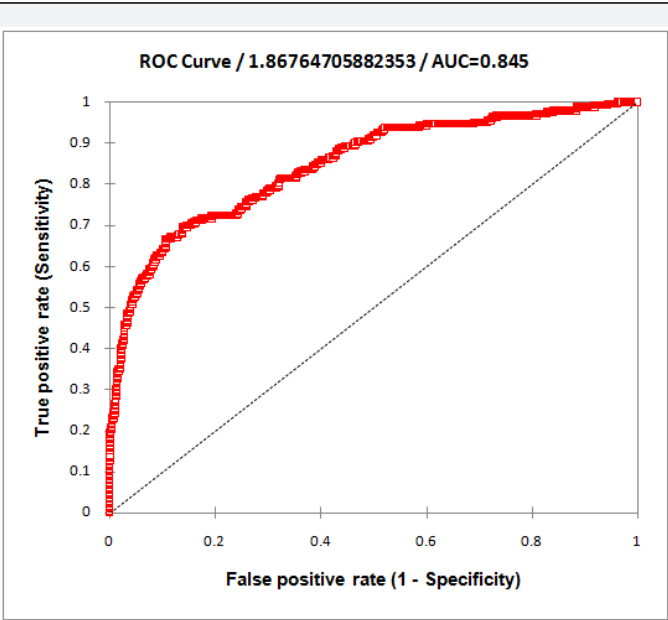

Figure 1: Represents chronic energy deficiency and waist hip ratio.

Nutrient needs during adolescence are higher than at any other time in the lifecycle, and failure to consume a healthy balanced diet during this time can have adverse effects on young people's well-being, energy and health. In addition to the impact on growth and development, a poor diet during this life stage can cause a number of immediate health problems, such as being overweight and obese in the short-term. WC measurements as potentially more accurate predictors of metabolic risk and type 2 diabetes, compared to WHO and IDF-recommended WC midway measurement or BMI, deserves further investigation [8].

\section{Conclusion}

Central obesity had significant effect on chronic heart disease, those girls have shown centrally obese in his study. They have chances to experience heart disease in future. 1-Normal 2-undernutrient.

\section{References}

1. WHO (2008) Waist Circumference and Waist-Hip Ratio, Report of a WHO Expert Consultation. World Health Organization, Geneva, Switzerland.

2. Ying X, Song ZY, Zhao CJ, Jiang Y (2010) Body mass index, waist circumference, and cardiometabolic risk factors in young and middleaged Chinese women. J Zhejiang Univ Sci B 11(9): 639-646.

3. Waist to Hip Ratio. freedieting.com.

4. Hajian-Tilaki K (2013) Receiver Operating Characteristic (ROC) Curve Analysis for Medical Diagnostic Test Evaluation Caspian. J Intern Med 4(2): 627-635.

5. Kavak V, Pilmane M, Kazoka D (2014) Body Mass Index, Waist Circumference and Waist-to-Hip-Ratio in the Prediction of Obesity in Turkish Teenagers Coll. Antropol 38(2): 445-451.

6. Li SS, Pan S, Ma YT1, Yang YN, Ma X, et al. (2014) Optimal cutoff of the waist-to-hip ratio for detecting cardiovascular risk factors among Han adults in Xinjiang. BMC Cardiovasc Disord 14: 93.

7. Lee CM, Huxley RR, Wildman RP, Woodward M (2008) Indices of abdominal obesity are better discriminators of cardiovascular risk factors than BMI: a meta-analysis. J Clin Epidemiol 61: 646-653.

8. Skrzypczak M, Szwed A, Pawlińska-Chmara R, Skrzypulec V (2007) Assessment of the BMI, WHR and W/Ht in pre- and postmenopausal women. Anthropological Review 70(1): 3-13.

9. Obuchowski NA (2006) An ROC-type measure of diagnostic accuracy when the gold standard is continuous-scale. Stat Med 25(3): 481-493.

10. Millar SR, Perry IJ, Broeck JVD, Phillips CM (2015) Optimal Central Obesity Measurement Site for Assessing Cardiometabolic and Type 2 Diabetes Risk in Middle-Aged Adults. PLoS One 10(6): e0129088. 
This work is licensed under Creative Commons Attribution 4.0 Licens DOI: 10.19080/GJAA.2017.01.555552

\section{Your next submission with Juniper Publishers} will reach you the below assets

- Quality Editorial service

- Swift Peer Review

- Reprints availability

- E-prints Service

- Manuscript Podcast for convenient understanding

- Global attainment for your research

- Manuscript accessibility in different formats

( Pdf, E-pub, Full Text, Audio)

- Unceasing customer service

Track the below URL for one-step submission https://juniperpublishers.com/online-submission.php 